\title{
Flow Boiling Heat Transfer Enhancement by Using ZnO-Water Nanofluids
}

\author{
Om Shankar Prajapati ${ }^{1}$ and Nirupam Rohatgi ${ }^{2}$ \\ ${ }^{1}$ Department of Mechanical Engineering, Rajasthan Technical University, Kota, Rajasthan 324010, India \\ ${ }^{2}$ Department of Mechanical Engineering, Malaviya National Institute of Technology, Jaipur, Rajasthan 302017, India
}

Correspondence should be addressed to Om Shankar Prajapati; omshankar.prajapati@gmail.com

Received 31 May 2013; Accepted 11 November 2013; Published 2 February 2014

Academic Editor: Mohamed Awad

Copyright (c) 2014 O. S. Prajapati and N. Rohatgi. This is an open access article distributed under the Creative Commons Attribution License, which permits unrestricted use, distribution, and reproduction in any medium, provided the original work is properly cited.

\begin{abstract}
Nanofluids are liquid suspensions containing nanoparticles that are smaller than $100 \mathrm{~nm}$. There is an increased interest in nanofluids as thermal conductivity of nanofluids is significantly higher than that of the base liquids. $\mathrm{ZnO}$-water nanofluids with volume concentration of $\mathrm{ZnO}$ particles varying from 0.0001 to $0.1 \%$ were prepared using ultrasonic vibration mixer. Thermal conductivity of the $\mathrm{ZnO}$-water fluids was investigated for different sonication time using thermal property analyzer (KD2 Pro). Thermal conductivity of nanofluids for a given concentration of nanoparticle varies with sonication time. Heat transfer coefficient and pressure drop in an annular test section with variable pressure (1-2.5 bar) and heat flux $\left(0-400 \mathrm{~kW} / \mathrm{m}^{2}\right)$ at constant mass flux of $400 \mathrm{~kg} / \mathrm{m}^{2}$ s were studied for samples having maximum thermal conductivity. Surface roughness of the heating rod was also measured before and after the experimentation. The study shows that heat transfer coefficient increases beyond the base fluid with pressure and concentration of $\mathrm{ZnO}$.
\end{abstract}

\section{Introduction}

Heat transfer enhancement is an important method to save energy in different engineering processes. Use of solid particles in conventional fluids, because of their higher thermal conductivity, has been considered for decades to enhance heat transfer. However, because of practical problems like fouling, sedimentation, and increase in pressure drop interest of the industry in this technique never really picked up. In recent years significant advances in nanotechnology have made it possible to overcome these problems by producing particles in nanometer size ranges.

A nanofluid is a fluid with a colloidal dispersion of nanosized particles of another substance in water or other base fluids. In a colloid two substances are distinguishable but can interact through weak surface molecular forces. The nanoparticles used in nanofluids commonly have an average size below $100 \mathrm{~nm}$. Relatively large surface area of nanoparticles increases the stability of nanofluid and reduces the problem of sedimentation of nanoparticles. Heat transfer increased with increase in surface area of nanoparticles compared to microparticles because of increased stability of nanofluids. A lot of research has been undergone for the last twenty years in pool boiling of nanofluids. You et al. [1] reported that nanofluids have great potential for enhancing the heat transfer coefficients and critical heat flux (CHF). They showed that nanofluids can improve the critical heat flux (CHF) by as much as $200 \%$. Kim [2] reported that heat transfer coefficient for Alumina and Zinc-oxide based nanofluid in flow boiling did not statistically improve, even for much higher mass fluxes at 1 bar. He also reported increased CHF for Alumina and Zinc-oxide based nanofluid. While nanofluids in pool boiling conditions are being studied broadly, data for nanofluid flow boiling, which is the situation of interest for the nuclear applications, are very scarce.

Nanofluids are gaining popularity among academic researchers and receiving more attention from industry as they continue to demonstrate improvements in heat transfer 
properties of liquid cooling processes. "Nanofluids" is the accepted nomenclature for slurries containing nanoparticles suspended in a base fluid. Conventional heat transfer fluids, including oil, water, and ethylene glycol mixture, are poor heat transfer fluids, since the thermal conductivity of these fluids plays an important role in the heat transfer coefficient between the heat transfer medium and the heat transfer surface. Therefore numerous measures have been taken to improve the thermal conductivity of these fluids by suspending nano/micro-or larger-sized particle materials in liquids [3].

Nanoparticle suspensions in fluids make a new innovative category of fluids, called nanofluids. These kinds of fluids are now of great interest not only for modifying heat transfer performance of fluids, but also for improving other characteristics such as mass transfer and rheological properties of fluids [4-7].

From a relatively limited amount of experimental data (see in particular [8-14]), it has been found that nanofluids generally possess thermal conductivities well higher than those of the base fluids.

Prajapati and Rajvanshi [15] measured the effect of $\mathrm{Al}_{2} \mathrm{O}_{3}$ water nanofluid on heat transfer characteristics in convection. They observed that heat transfer increases with addition of the $\mathrm{Al}_{2} \mathrm{O}_{3}$ nanoparticles in the base fluid because of increased thermal conductivity of $\mathrm{Al}_{2} \mathrm{O}_{3}$ nanofluid, heat transfer through increased solid-liquid interface layers, heat conduction through nanoparticles, and nanoparticle driven natural convection.

He et al. [16] observed enhancement in the convective heat transfer coefficient in laminar as well as turbulent flow regimes and the enhancement increased with increase in particle concentration. The enhancement in the laminar flow regime was much smaller than that in the turbulent flow regime. At $\mathrm{Re}=1500$, the maximum enhancement was about $12 \%$ for nanofluid having $1.1 \%$ of $\mathrm{TiO}_{2}$ by volume, whereas at $\operatorname{Re}=5900$, the maximum enhancement for the same nanofluid, that is, $1.1 \%$ of $\mathrm{TiO}_{2}$ by volume, exceeded by $40 \%$. Experiments were also conducted for nanofluid having fixed volume $\%$ of $\mathrm{TiO}_{2}$ but with different sizes of $\mathrm{TiO}_{2}$ nanoparticles. The average particle size had marginal effect on heat transfer.

Duangthongsuk and Wongwises [17] presented experimental investigations on convective heat transfer performance and flow characteristic of a $\mathrm{TiO}_{2}$-water nanofluid for a horizontal double tube counterflow heat exchanger. Experiments were carried out under turbulent flow conditions. The results indicate that heat transfer coefficient increases with increase in Reynolds number. The convective heat transfer coefficient of the nanofluid was higher than that of the base fluid (water) at any given Reynolds number. The nanofluid having $0.2 \%$ of $\mathrm{TiO}_{2}$ by volume had approximately $6-11 \%$ higher heat transfer coefficient than that of the pure water. The convective heat transfer coefficient increased with increase in Reynolds number and it increased with increase in mass flow rate of the heating fluid.

Heris et al. [18] observed that nanofluids can conduct heat one order of magnitude faster than scientists had predicted possible. Because of their considerable promise, nanofluids have become a rapidly emerging field where nanoscale science and engineering meet.

Bang et al. [19] measured the effect of pressure on heat transfer coefficient. Experimental data for only two pressures (2 and 16 bar) were compared. At low vapor quality where the slug flow pattern seemed to be dominant, the heat transfer coefficient was slightly higher at the higher pressure. At high vapor quality where the flow pattern is annular flow, the effect of pressure was not significant.

Rana et al. [20] performed experiments in subcooled flow boiling of $\mathrm{ZnO}$-water nanofluids with different low particle concentrations $(\leq 0.01$ volume $\%)$ in horizontal annulus at heat fluxes from 100 to $450 \mathrm{~kW} / \mathrm{m}^{2}$ and flow rates from 0.1 to $0.175 \mathrm{lps}$ at 1 bar inlet pressure and constant subcooling of $20^{\circ} \mathrm{C}$ to determine bubble behavior and heat transfer with flow rates of $\mathrm{ZnO}$. They observed that increase in heat flux leads to increase in bubble diameter; the heat transfer coefficient increases with increase in heat flux and particle volume fraction of $\mathrm{ZnO}$.

Moosavi et al. [21] measured thermal conductivity, viscosity, and surface tension of $\mathrm{ZnO}$ nanofluids with ethylene glycol (EG) and glycerol (G) as the base fluids. They observed that the thermal conductivity of $\mathrm{ZnO} / \mathrm{EG}$ and $\mathrm{ZnO} / \mathrm{G}$ nanofluids increased nonlinearly up to $10.5 \%$ and $7.2 \%$, respectively, as the volume fraction of nanoparticles increased up to $3 \%$ by volume. The ratio of the viscosity of the nanofluid and the viscosity of the base fluid increased with increase in concentration and decrease in temperature. The ratio of surface tension of the nanofluid and the surface tension of the base fluid increased with increase in the volume fraction of the solid nanoparticles.

Based on the following key properties, $\mathrm{ZnO}$ nanomaterial is selected for experimentation:

(1) corrosive resistant,

(2) the antibacterial behavior,

(3) good thermal conductivity,

(4) easy availability in purity ranges from $94 \%$ to $99.9 \%$,

(5) excellent size and shape capability,

(6) low cost.

By suspending nanophase particles in heating or cooling fluids, the heat transfer performance of the fluid can be significantly improved. The main reasons for this effect are listed below.

(1) The suspended nanoparticles increase the effective thermal conductivity $(\mathrm{W} / \mathrm{m}, \mathrm{K})$ of the fluid. Thermal conductivity of nanoparticles is in order of $1000+$ when mixed with fluids of low thermal conductivity, that is, of the order of 0.01 to 1 ; the mixture obtained has higher thermal conductivity compared to the base fluid.

(2) The interaction and collision among particles, fluid, and the flow passage surface are intensified.

(3) The mixing fluctuation and turbulence of the fluid are intensified by Brownian motion due to increased energy level of electron at higher temperature. 


\section{Experimental Setup}

Preparation of nanofluid is the first key step towards using nanophase particles to enhance the heat transfer performance of conventional fluids. The nanofluid does not simply refer to a liquid-solid mixture of base fluid and nanoparticles. A nanofluid has some special requirements such as uniformity, stability, low agglomeration of particles, and no change in chemical and physical properties of the fluid. In general, the following are the effective methods used for preparation of suspensions: (1) changing the $\mathrm{pH}$ value of suspension, (2) using surface activators and/or dispersants, and (3) using ultrasonic vibrations. These methods can change the surface properties of the suspended particles and can be used to suppress the formation of particle clusters in order to obtain stable suspensions. The use of these techniques depends on the application for which the nanofluid is to be used.

Toshcon make ultrasonic vibration mixer (UVM) of $27 \pm$ $3 \mathrm{kHz}$ frequency and $1500 \mathrm{~W}$ ultrasonic capacity was used to prepare the nanofluids. In UVM, the ultrasonic energy is produced by converting electrical energy into mechanical vibrations by using generator and piezoelectric transducers. The required weight of the nanoparticles was mixed with distilled water in UVM and vibrated for 3 to 4 hours. Prepared nanofluid was placed in the storage reservoir. An immersed electrical heater was provided in the storage reservoir to regulate the temperature of the nanofluid. It also consists of temperature control device. The storage reservoir was made of stainless steel.

The closed fluid loop test facility (Figure 1) of 10liter capacity consists of mainly an ultrasonic vibration mixer, storage reservoir, circulating pump, flow meter, heater inserted horizontal annular test section, condenser, and heat exchanger. The working fluid is pumped from the reservoir to the test section through flow meter that measures fluid flow rate. The working fluid or the mixture of working fluid and steam from the exit of the test section passes through a horizontal condenser and counterflow heat exchanger before returning to the reservoir. In boiling flow, condenser condenses the steam into water and heat exchanger reduces the excess temperature and controls the temperature of working fluid before recirculation. The inlet temperature of the working fluid at test section is maintained constant by using an electrical heater controlled by a temperature controller in the reservoir tank. The fluid loop was designed to work in range of variable parameters like heat supply, inlet pressure, type of the fluid, flow rate, inlet temperature of the fluid, and the degree of subcooling.

Pressure drop in test section also measured for varying concentration of nanofluids with pressure sensors at inlet and outlet. The annular test section as shown in Figure 2 and photograph in Figure 3 is $780 \mathrm{~mm}$ long and consists of an electrically heated rod and an outer borosilicate glass tube of $21.8 \mathrm{~mm}$ inner diameter. The heater is $12.7 \mathrm{~mm}$ diameter hollow stainless steel rod welded to solid copper rods at both ends. The test section is easily dismountable. The heater rod is fitted with transparent glass tube by two teflon corks at both ends. The test section was not insulated to facilitate the visualization studies. Adhesive was applied at the ends
TABLE 1: Experimental range.

\begin{tabular}{lcc}
\hline $\begin{array}{l}\text { Serial } \\
\text { number }\end{array}$ & Parameter & Range \\
\hline 1 & Pressure (bar) & $1-2.5$ \\
2 & ZnO volume fraction (\%) & $0.0001-0.1$ \\
3 & Heat flux $\left(\mathrm{kW} / \mathrm{m}^{2}\right)$ & $0-400$ \\
4 & Diameter of nanoparticles $(\mathrm{nm})$ & $30-50$ \\
\hline
\end{tabular}

TABLE 2: Results of uncertainty analysis.

\begin{tabular}{lcc}
\hline Serial number & Parameter & Uncertainty (\%) \\
\hline 1 & Temperature & \pm 0.4 \\
2 & Pressure & \pm 1.58 \\
3 & Volumetric flow & \pm 1.6 \\
4 & Heat flux & \pm 1.14 \\
\hline
\end{tabular}

of tubes over teflon corks and thermocouples to remove leakage problem at high heat flux. In the glass tube, the fluid flows over the surface of the heater rod. The heated length of $500 \mathrm{~mm}$ is located $230 \mathrm{~mm}$ downstream of the inlet plenum and thus allowing for the flow to fully develop. An input $415 \mathrm{~V}$ 3-phase AC power is stepped down to $0-32 \mathrm{~V} \mathrm{DC}$ power by using $64 \mathrm{kVA}$ DC regulated power supply by which a large range of heat fluxes are applied to the test section.

Two pressure transducers are installed at both ends of the test section to measure the pressure drop along the tube. Static pressure at the inlet and the outlet of the test section are measured using Keller make pressure sensors which have a range of $1-10$ bar with an accuracy of $\pm 0.1 \%$. The pressure drop in single-phase flow and two-phase flow of nanofluids was measured. Measured data including pressures and temperatures are recorded by a data acquisition system (Omega, OMB-DAQ-55) which is connected to a computer.

Temperatures at the inlet and the outlet of the test section and the heater surface were measured with J-type ungrounded thermocouples. Temperatures at various locations on the surface of the heater rod were measured using five miniature thermocouples which were embedded on it. All the thermocouples were connected to the data acquisition system. 4-wire turbine type flow meter (Electronet, FL-204) with flow range of $0.02-0.3$ lps was used for measuring the mass flow rate. Its time response was $100 \mathrm{~ms}$ with accuracy of $\pm 1 \%$.

A hollow pipe of stainless steel was fitted in the place of test section to clean the experimental test fluid loop with 13.88 normal $\mathrm{H}_{2} \mathrm{SO}_{4}$ in distilled water before final cleaning by distilled water at $90^{\circ} \mathrm{C}$ and atmospheric pressure to remove oxides and other residues after every experimental set. The experimented test section was used to measure surface roughness separately. A new heater rod of test section was cleaned with very fine (grade P-220) sand paper to maintain similar surface characteristics of the test surface.

The experimental boundary conditions and results of uncertainty analysis for measured parameters are shown in Tables 1 and 2, respectively. The experimental uncertainty of the present work was determined by ASME guidelines on 


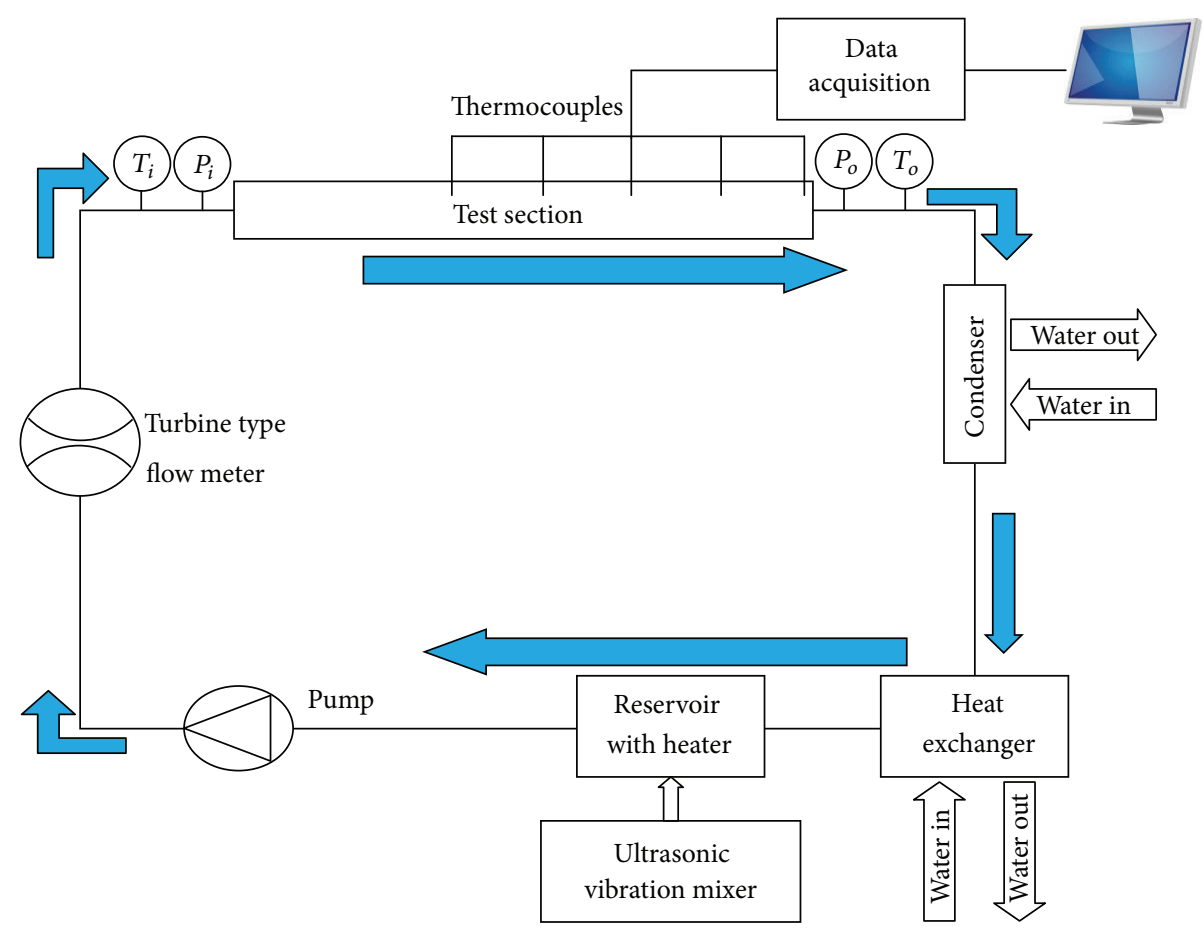

Figure 1: Experimental flow fluid loop.

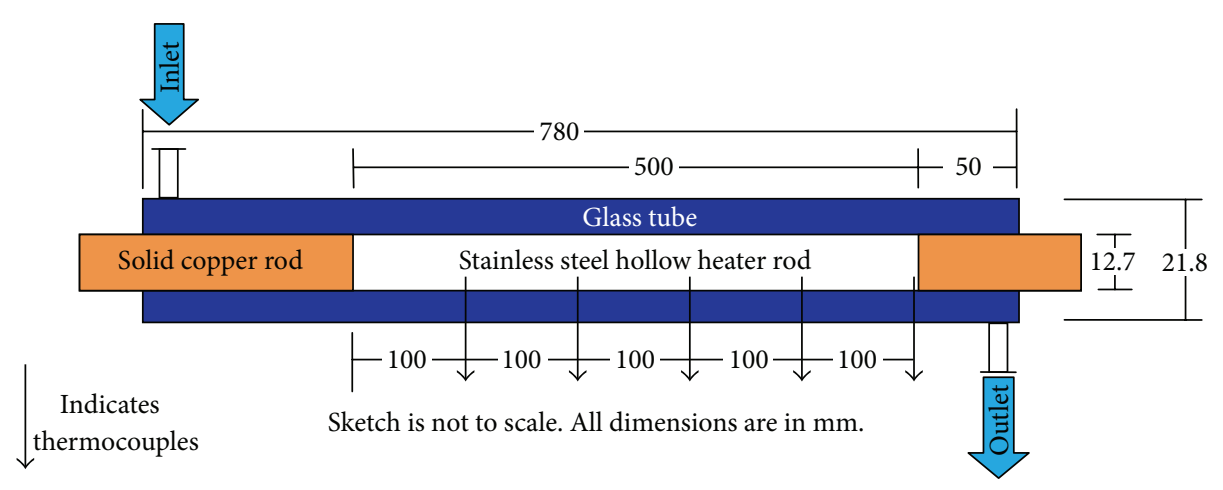

FIgURE 2: Annular test section.

uncertainties in experimental measurements in multiphase flow [22].

\section{Experimental Procedure}

The following procedure was adopted for conducting the experiment.

(1) According to the required concentration of nanofluid, the required weight of the nanoparticles was calculated and this amount of nanoparticles was mixed with distilled water.

(2) $\mathrm{ZnO}$-water nanofluid was prepared in ultrasonic vibration mixer machine for 3 to $4 \mathrm{hrs}$ based on maximum thermal conductivity.

(3) Thermal conductivity of $\mathrm{ZnO}$-water nanofluid was measured with thermal property analyzer KD2-Pro.
(4) The test section and heater surface were cleaned with dilute $\mathrm{H}_{2} \mathrm{SO}_{4}$ solution to remove oxides and fouling residues.

(5) The fluid loop was filled with working fluid, distilled water, or $\mathrm{ZnO}$-water nanofluid.

(6) Degassing of distilled water or $\mathrm{ZnO}$-water nanofluid was done to remove dissolved and entrapped air from the fluid loop using degassing valve. This process was repeated 2-3 times before each experiment until no bubbles were observed.

(7) After degassing, parameters like pressure, heat flux, and inlet temperature were set according to experimental boundary conditions.

(8) Heat flux was gradually increased upto $0.4 \mathrm{MW} / \mathrm{m}^{2}$. 


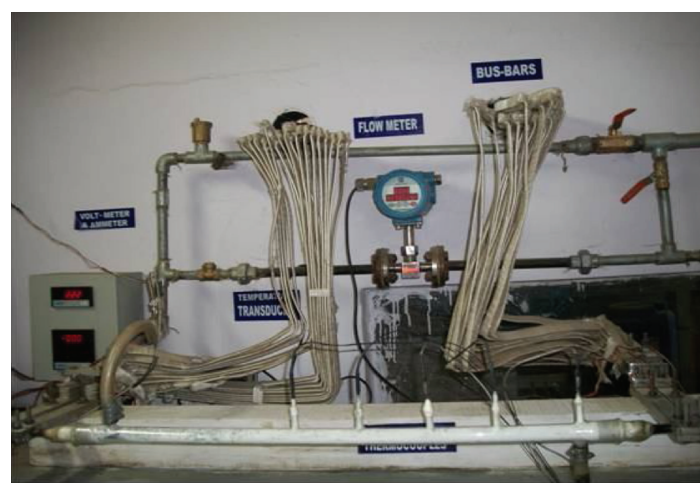

Figure 3: Photograph of test setup during experiment.

(9) For each concentration of $\mathrm{ZnO}$-water nanofluid and pressure, temperature, voltage, and current were measured.

(10) For the next set, the pressure and the \% volume fraction of nanofluids were changed and similar readings were taken at each heat flux.

(11) Surface roughness measured for bare heater rod and nanoparticles coated heater rod after a set of experiments for each \% volume fraction of nanofluids.

\section{Results}

The heat transfer coefficient, $h$, is calculated from knowledge of Newton's law of cooling:

$$
h=\frac{q "}{T_{s}-T_{b}} .
$$

Here heat flux $q^{\prime \prime}$ calculated as joule power $(V * I)$ divided by area; and the surface temperature, $T_{s}$ and the bulk temperature, $T_{b}$ measured at the steady-state condition by ensuring that temperatures of all the thermocouples have become steady. The surface temperature, $T_{s}$ was the average of all the five imbedded thermocouples.

Experimental data in Figure 4 shows heat transfer coefficient of distilled water. Results show that heat transfer increases with heat flux for all pressures due to increased energy gain by the water.

Experimental data in Figures 5, 6, 7, and 8 shows heat transfer coefficient of $0.0001 \% \mathrm{ZnO}$-water nanofluid, $0.001 \%$ $\mathrm{ZnO}$-water nanofluid, $0.01 \% \mathrm{ZnO}$-water nanofluid, and $0.1 \% \mathrm{ZnO}$-water nanofluid. Results show that heat transfer increases with heat flux for all concentrations of $\mathrm{ZnO}$-water nanofluids due to increased energy gain by the nanoparticles, which is in similar trend with previous researches [20]. The increase in heat transfer coefficient was significant at $0.1 \%$ volume concentration of nanoparticles because at higher concentration of nanoparticles (0.1\%): $120 \%$ increased thermal conductivity of $\mathrm{ZnO}$-water nanofluid, $1367 \%$ increased surface roughness of heater rod due to deposition of $\mathrm{ZnO}$ water nanofluid, the nanoparticles were deposited more on heater surface thereby increasing the surface area of heater

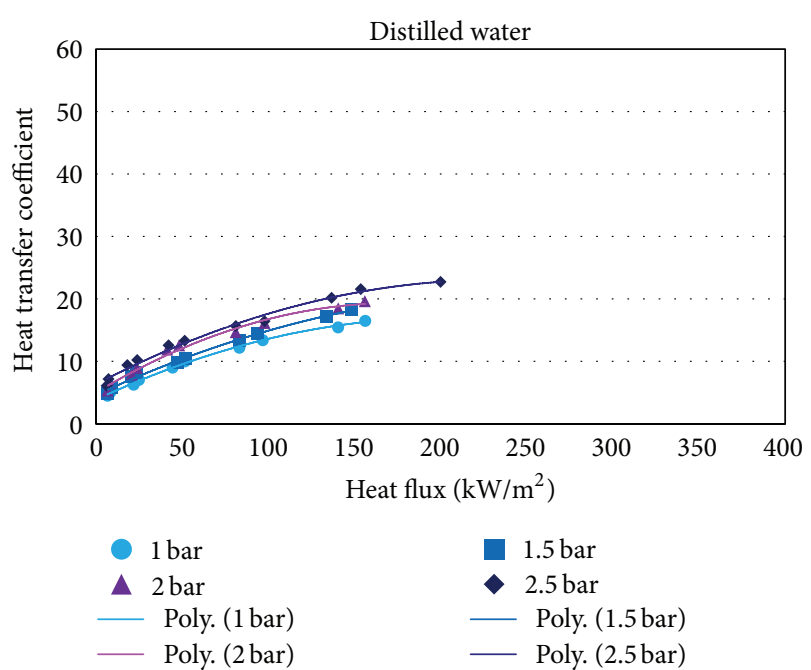

FIGURE 4: Variation of heat transfer coefficient, $h\left(\mathrm{~kW} / \mathrm{m}^{2} \mathrm{~K}\right)$ of distilled water with heat flux at $400 \mathrm{~kg} / \mathrm{m}^{2} \mathrm{~s}$ mass flow rate.

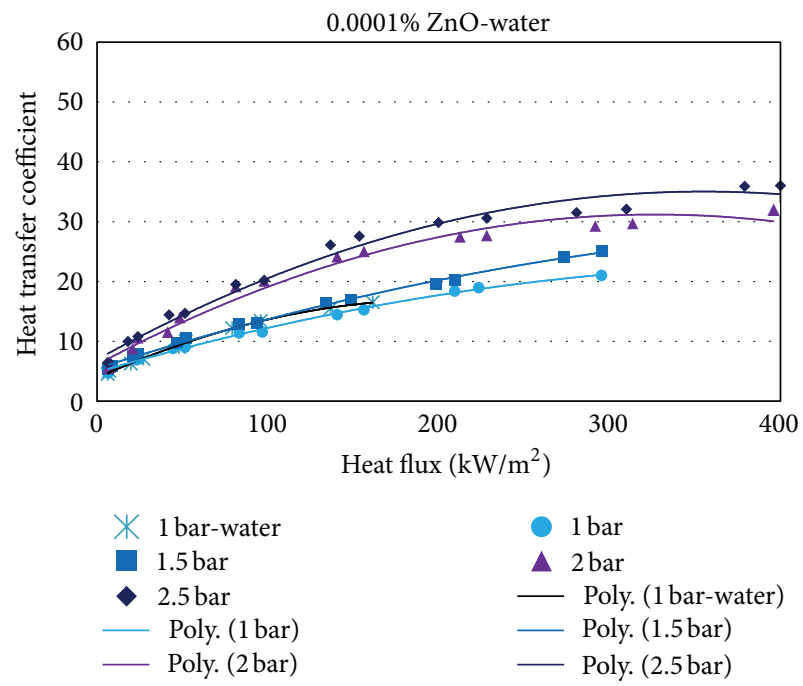

FIGURE 5: Variation of heat transfer coefficient, $h\left(\mathrm{~kW} / \mathrm{m}^{2} \mathrm{~K}\right)$ of $\mathrm{ZnO}$-water nanofluid with heat flux at $0.0001 \% \mathrm{ZnO}$ nanoparticle volume fraction and $400 \mathrm{~kg} / \mathrm{m}^{2}$ s mass flow rate.

rod and thus increasing the heat transfer by convection also due to increased Brownian motion, particle driven natural convection, and increased conduction between nanoparticles.

The heat transfer coefficient also increased with applied pressure because at higher pressure effective cooling of heater rod was observed possibly due to increased Brownian motion, particle driven natural convection and conduction, between nanoparticles via more force applied at same heating area.

Figure 9 shows pressure drop $\Delta P$ (bar) in an annular test section for different $\mathrm{ZnO}$-water nanofluid with varying concentration of $\mathrm{ZnO}$. There was no significant pressure drop observed at lower concentrations; however at higher 

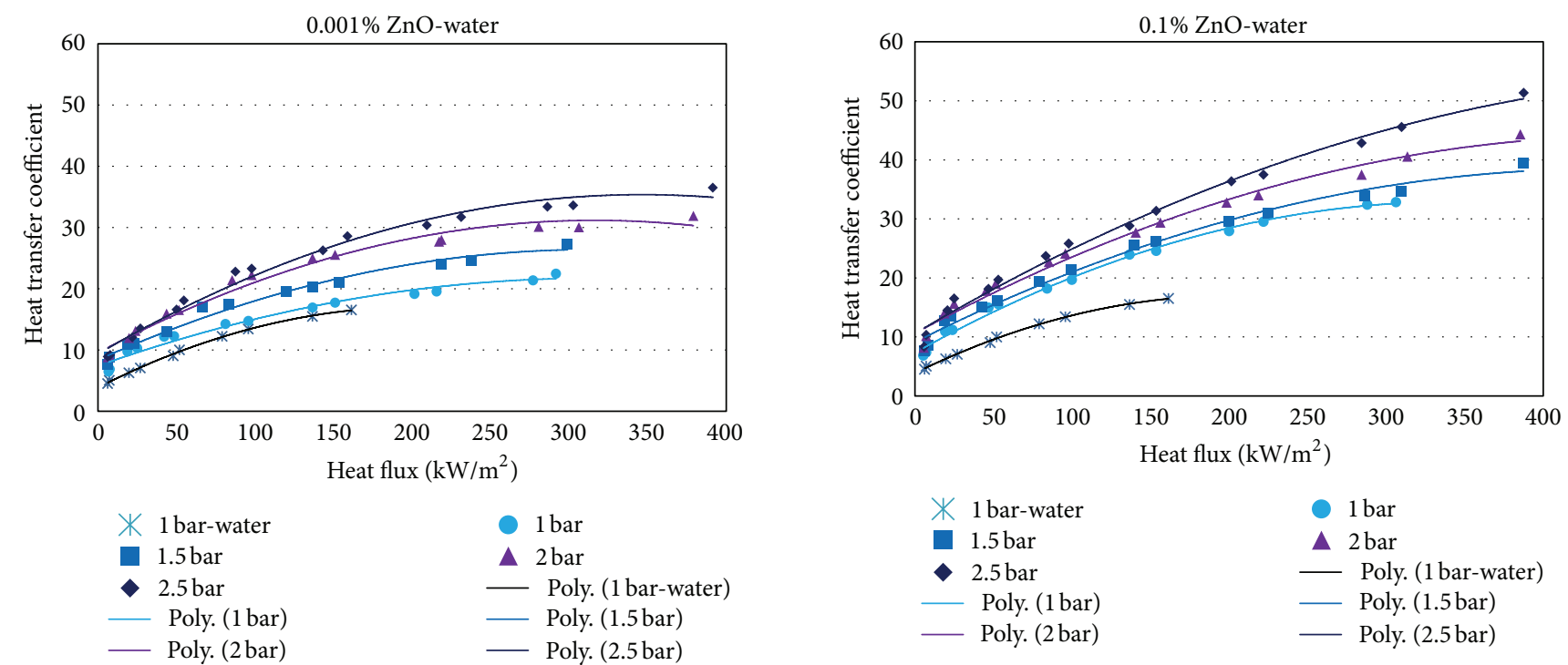

FIGURE 6: Variation of heat transfer coefficient, $h\left(\mathrm{~kW} / \mathrm{m}^{2} \mathrm{~K}\right)$, of $\mathrm{ZnO}$-water nanofluid with heat flux at $0.001 \% \mathrm{ZnO}$ nanoparticle volume fraction and $400 \mathrm{~kg} / \mathrm{m}^{2} \mathrm{~s}$ mass flow rate.
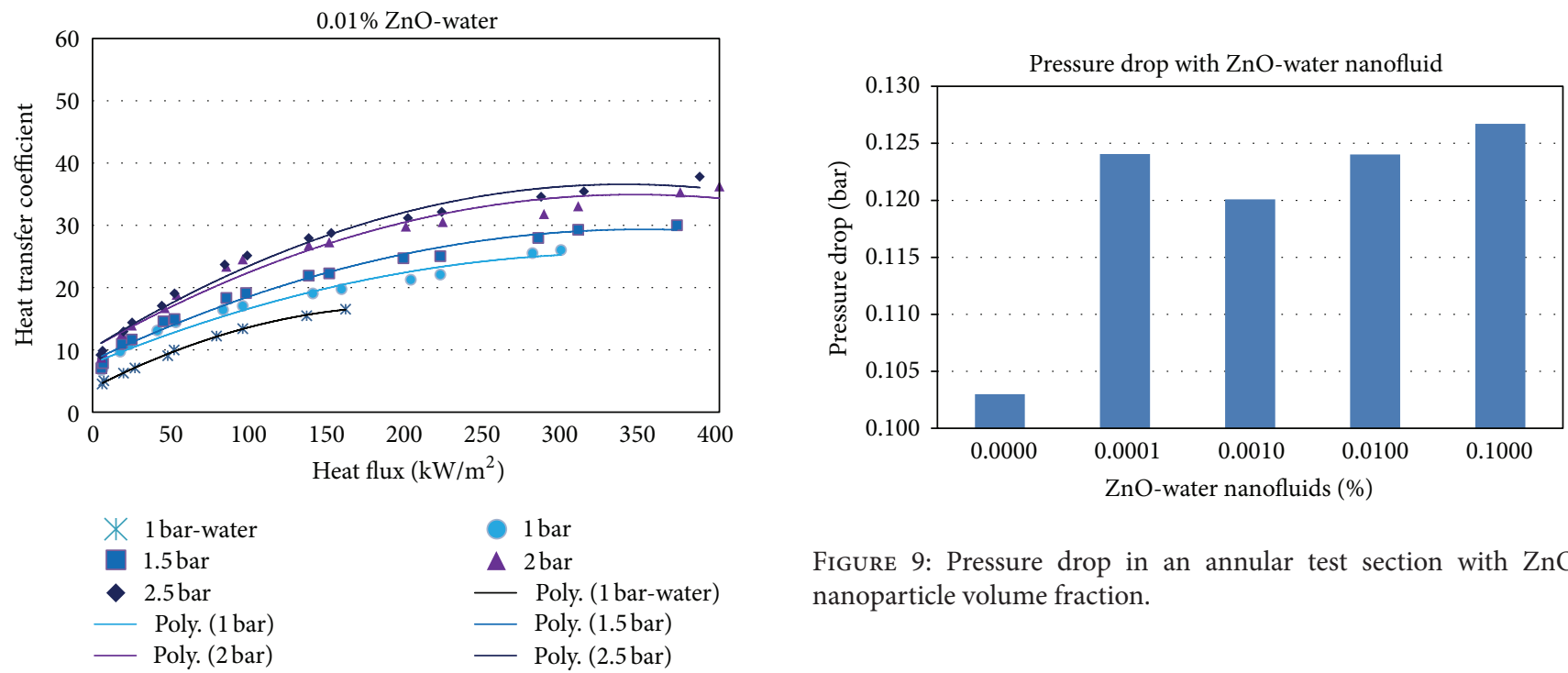

Figure 9: Pressure drop in an annular test section with $\mathrm{ZnO}$ nanoparticle volume fraction.

FIGURE 7: Variation of heat transfer coefficient, $h\left(\mathrm{~kW} / \mathrm{m}^{2} \mathrm{~K}\right)$, of $\mathrm{ZnO}$-water nanofluid with heat flux at $0.01 \% \mathrm{ZnO}$ nanoparticle volume fraction and $400 \mathrm{~kg} / \mathrm{m}^{2} \mathrm{~s}$ mass flow rate.

concentrations $(0.001 \%$ to $0.1 \%)$ pressure drop was increased due to increased viscosity of nanofluids.

Figure 10 shows that the surface roughness, $\mathrm{Ra}(\mu \mathrm{m})$, of heater rod for $\mathrm{ZnO}$-water nanofluid increases gradually with increase in concentration of $\mathrm{ZnO}$ particles in the nanofluid because of deposition of nanoparticles on heating surface area.

\section{Conclusion}

An experimental facility was developed to study heat transfer characteristics of $\mathrm{ZnO}$-water nanofluid. The working fluid

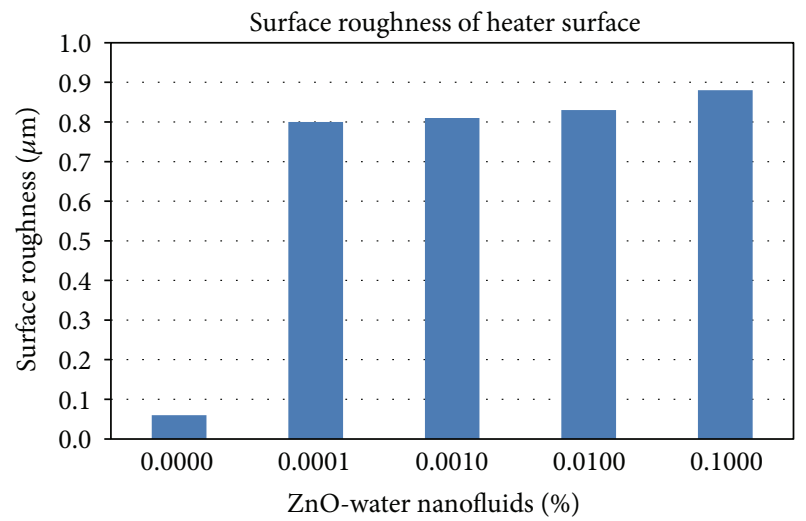

FIgURE 10: The surface roughness of heater rod of deposited $\mathrm{ZnO}$ water nanoparticles with volume fraction. 
was electrically heated in horizontal annular test section. All the instruments in test setup were properly calibrated as per guidelines given by American Society of Mechanical Engineers. Flow boiling heat transfer experiments in subcooled region were carried out to study heat transfer characteristics of $\mathrm{ZnO}$-water nanofluid. The results of the present investigation are summarized as follows.

(1) Heat transfer coefficient increases by $126 \%$ over water with applied pressure and particle volume fraction of $\mathrm{ZnO}$-water nanofluid within the given range of heat flux adopted.

(2) No significant pressure drop change relative to water only was observed with low concentrations of nanofluid but $23 \%$ pressure drop increases with $0.1 \%$ concentration of $\mathrm{ZnO}$ particles in the nanofluid.

(3) The surface roughness of the heating surface increases by $1367 \%$ with increase in concentration of $\mathrm{ZnO}$ particles in the nanofluid over the water.

\section{Conflict of Interests}

The authors declare that there is no conflict of interests regarding the publication of this paper.

\section{Acknowledgments}

The guidance by Late Professor A. K. Rajvanshi and the financial help from the "Board of Research in Nuclear Science (BRNS), Department of Atomic Energy, India” (Sanction no. 2009/36/95-BRNS/3234) are gratefully acknowledged.

\section{References}

[1] S. M. You, J. H. Kim, and K. H. Kim, "Effect of nanoparticles on critical heat flux of water in pool boiling heat transfer," Applied Physics Letters, vol. 83, no. 16, pp. 3374-3376, 2003.

[2] S. J. Kim, Subcooled flow boiling heat transfer and critical heat flux in water-based nanofluids at low pressure [Ph.D. thesis], Nuclear Science and Engineering Department, Massachusetts Institute of Technology, 2009.

[3] S. Kakaç and A. Pramuanjaroenkij, "Review of convective heat transfer enhancement with nanofluids," International Journal of Heat and Mass Transfer, vol. 52, no. 13-14, pp. 3187-3196, 2009.

[4] X. Ma, F. Su, J. Chen, T. Bai, and Z. Han, "Enhancement of bubble absorption process using a CNTs-ammonia binary nanofluid," International Communications in Heat and Mass Transfer, vol. 36, no. 7, pp. 657-660, 2009.

[5] O. N. Sara, F. Içer, S. Yapici, and B. Sahin, "Effect of suspended $\mathrm{CuO}$ nanoparticles on mass transfer to a rotating disc electrode," Experimental Thermal and Fluid Science, vol. 35, no. 3, pp. 558564, 2011.

[6] E. Nagy, T. Feczkó, and B. Koroknai, "Enhancement of oxygen mass transfer rate in the presence of nanosized particles," Chemical Engineering Science, vol. 62, no. 24, pp. 7391-7398, 2007.

[7] P. K. Namburu, D. P. Kulkarni, D. Misra, and D. K. Das, "Viscosity of copper oxide nanoparticles dispersed in ethylene glycol and water mixture," Experimental Thermal and Fluid Science, vol. 32, no. 2, pp. 397-402, 2007.
[8] H. Masuda, A. Ebata, K. Teramae, and N. Hishinuma, "Alteration of thermal conductivity and viscosity of liquid by dispersing ultra-fine particles (dispersions of $\gamma-\mathrm{Al}_{2} \mathrm{O}_{3}, \mathrm{SiO}_{2}$, and $\mathrm{TiO}_{2}$ ultra-fine particles)," Netsu Bussei, vol. 4, no. 4, pp. 227-233, 1993.

[9] X. Wang, X. Xu, and S. U. S. Choi, "Thermal conductivity of nanoparticle-fluid mixture," Journal of Thermophysics and Heat Transfer, vol. 13, no. 4, pp. 474-480, 1999.

[10] C. H. Chon, K. D. Kihm, S. P. Lee, and S. U. S. Choi, "Empirical correlation finding the role of temperature and particle size for nanofluid $\left(\mathrm{Al}_{2} \mathrm{O}_{3}\right)$ thermal conductivity enhancement," Applied Physics Letters, vol. 87, no. 15, Article ID 153107, pp. 1-3, 2005.

[11] S. U. S. Choi, Z. G. Zhang, W. Yu, F. E. Lockwood, and E. A. Grulke, "Anomalous thermal conductivity enhancement in nanotube suspensions," Applied Physics Letters, vol. 79, no. 14, pp. 2252-2254, 2001.

[12] J. A. Eastman, S. U. S. Choi, S. Li, W. Yu, and L. J. Thompson, "Anomalously increased effective thermal conductivities of ethylene glycol-based nanofluids containing copper nanoparticles," Applied Physics Letters, vol. 78, no. 6, pp. 718-720, 2001.

[13] G. Roy, C. T. Nguyen, D. Doucet, S. Suiro, and T. Maré, “Temperature dependent thermal conductivity evaluation of alumina based nano-fluids," in Proceedings of the 13th International Symposium on Hyphenated Techniques in Chromatography and Separation Technology (IHTC '06), p. 12, Begell House, Sydney, Australia, August 2006.

[14] H. A. Mintsa, G. Roy, C. T. Nguyen, and D. Doucet, "New temperature dependent thermal conductivity data for waterbased nanofluids," International Journal of Thermal Sciences, vol. 48, no. 2, pp. 363-371, 2009.

[15] O. S. Prajapati and A. K. Rajvanshi, " $\mathrm{Al}_{2} \mathrm{O}_{3}$-water nanofluids in convective heat transfer," Applied Mechanics and Materials, vol. 110-116, pp. 3667-3672, 2012.

[16] Y. He, Y. Jin, H. Chen, Y. Ding, D. Cang, and H. Lu, "Heat transfer and flow behaviour of aqueous suspensions of $\mathrm{TiO}_{2}$ nanoparticles (nanofluids) flowing upward through a vertical pipe," International Journal of Heat and Mass Transfer, vol. 50, no. 11-12, pp. 2272-2281, 2007.

[17] W. Duangthongsuk and S. Wongwises, "Heat transfer enhancement and pressure drop characteristics of $\mathrm{TiO}_{2}$-water nanofluid in a double-tube counter flow heat exchanger," International Journal of Heat and Mass Transfer, vol. 52, no. 7-8, pp. 20592067, 2009.

[18] S. Z. Heris, M. N. Esfahany, and S. G. Etemad, "Experimental investigation of convective heat transfer of $\mathrm{Al}_{2} \mathrm{O}_{3}$ /water nanofluid in circular tube," International Journal of Heat and Fluid Flow, vol. 28, no. 2, pp. 203-210, 2007.

[19] K. H. Bang, K. K. Kim, S. K. Lee, and B. W. Lee, "Pressure effect on flow boiling heat transfer of water in minichannels," International Journal of Thermal Sciences, vol. 50, no. 3, pp. 280 286, 2011.

[20] K. B. Rana, A. K. Rajvanshi, and G. D. Agrawal, "A visualization study of flow boiling heat transfer with nanofluids," Journal of Visualization, vol. 16, pp. 133-143, 2013.

[21] M. Moosavi, E. K. Goharshadi, and A. Youssefi, "Fabrication, characterization, and measurement of some physicochemical properties of $\mathrm{ZnO}$ nanofluids," International Journal of Heat and Fluid Flow, vol. 31, no. 4, pp. 599-605, 2010.

[22] R. B. Abernethy, R. P. Benedict, and R. B. Dowdell, "ASME measurement-uncertainty," Journal of Fluids Engineering, vol. 107, no. 2, pp. 161-164, 1983. 


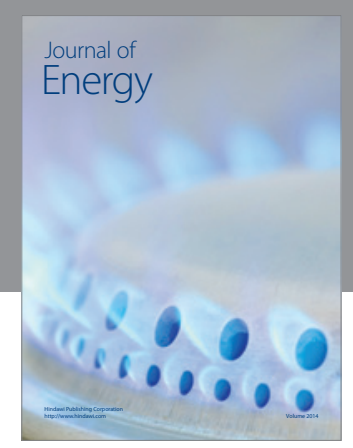

Journal of

Industrial Engineering
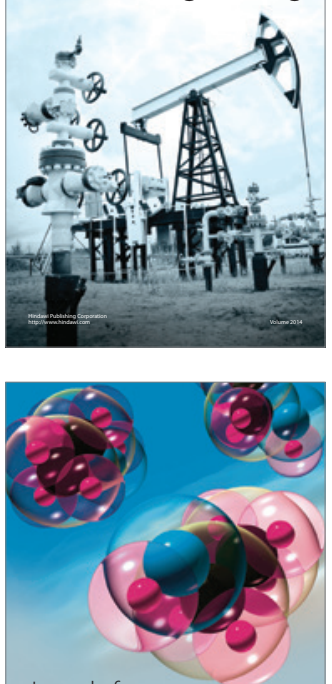

Fuels
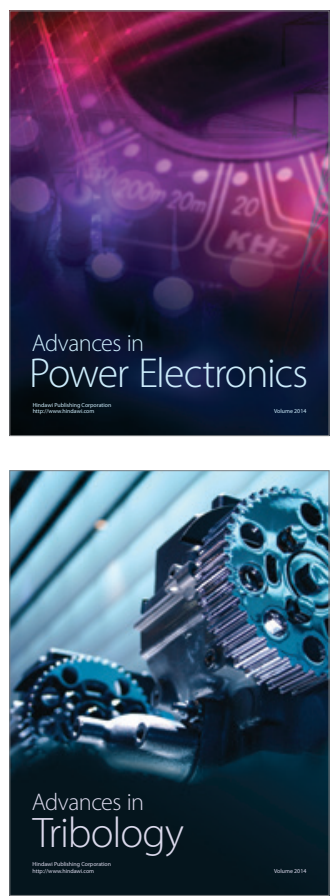

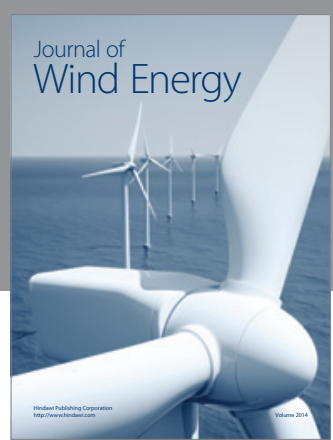

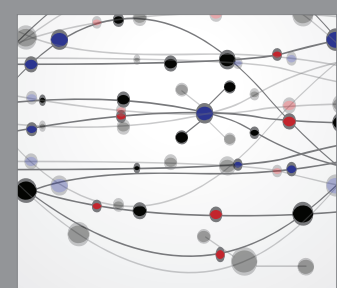

The Scientific World Journal

Submit your manuscripts at http://www.hindawi.com

Journal of

Structures
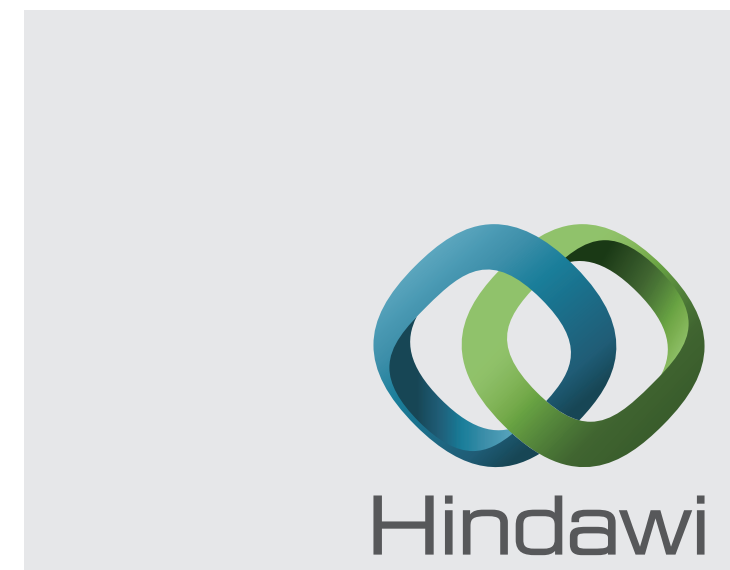

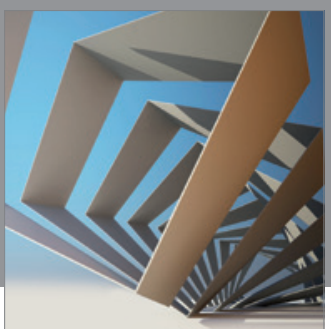

Rotating

Machinery
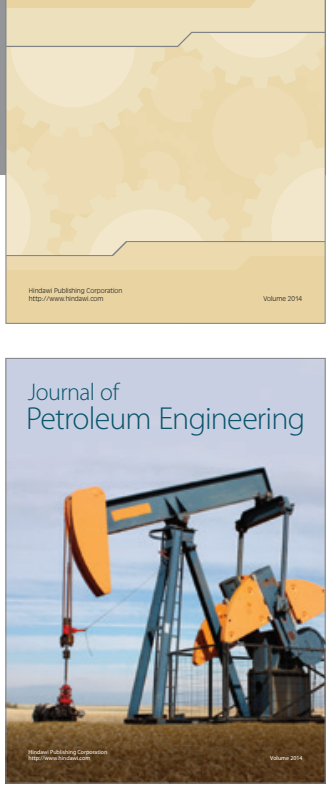

Journal of

Solar Energy
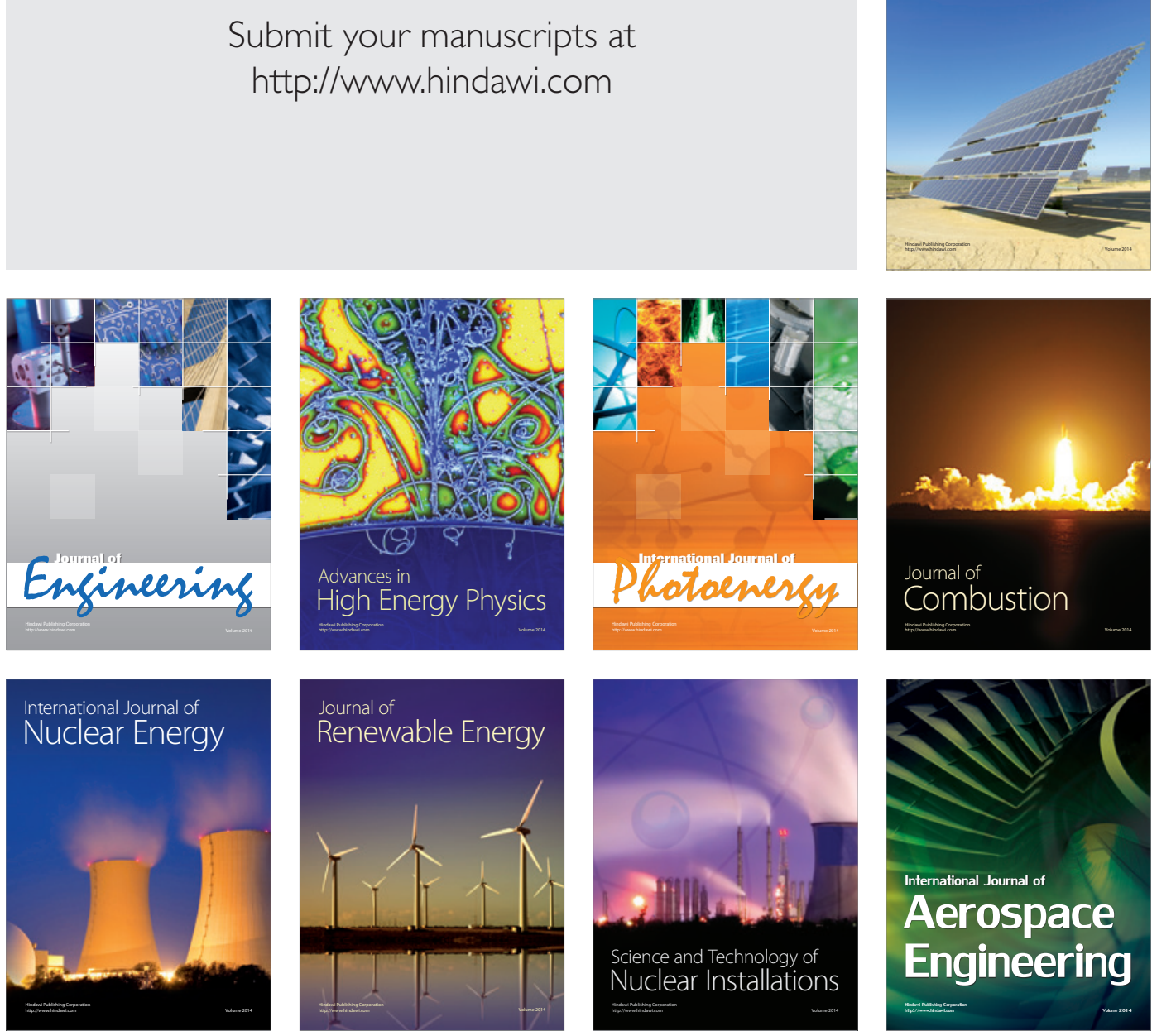